\title{
A rare case of fourth consecutive fallopian tube ectopic pregnancy
}

\section{Divya Pandey*, Teena Nagar, Shakti Sharma, Sudha Salhan}

Department of Obstetrics \& Gynaecology, NDMC Medical College and Hindu Rao Hospital, Delhi-7, India

Received: 16 January 2015

Accepted: 16 February 2015

\author{
*Correspondence: \\ Dr. Divya Pandey, \\ E-mail: dr_devya1@yahoo.co.in
}

Copyright: () the author(s), publisher and licensee Medip Academy. This is an open-access article distributed under the terms of the Creative Commons Attribution Non-Commercial License, which permits unrestricted non-commercial use, distribution, and reproduction in any medium, provided the original work is properly cited.

\begin{abstract}
We present a case of consecutive fourth tubal ectopic in a patient which was managed by emergency laparotomy and salpingectomy. The first two tubal ectopic pregnancies occurred on the right side while the subsequent two occurred on the contralateral side. The patient was planned for IVF-ET.
\end{abstract}

Keywords: Ectopic pregnancy, Recurrent tubal ectopic, Salpingectomy

\section{INTRODUCTION}

Ectopic pregnancy is one of the major causes of maternal morbidity and mortality in the first trimester of pregnancy. More than $95 \%$ of ectopic pregnancies occur in the fallopian tubes, other sites being infrequent. ${ }^{1}$ The recurrence rate of ectopic pregnancy after one previous ectopic is approximately $15 \%$ and increases to about $30 \%$ after two ectopic pregnancies. ${ }^{2,3}$

Apart from a few case reports of consecutive three ectopic pregnancies, the occurrence of fourth tubal ectopic pregnancy has not been reported so far. ${ }^{4-9}$

We hereby present the case of a female who had four consecutive tubal ectopic pregnancies along with discussion and review of literature regarding the management of recurrent ectopic pregnancies.

\section{CASE REPORT}

A 31 years old fourth gravida, illiterate female with previous three ectopic pregnancies presented in gynaecology casualty with complaints of sudden severe lower abdominal pain and vaginal bleeding following 8 weeks amenorrhoea. Her previous cycles were regular and normal in flow, amount and duration. She had no prior antenatal visit. The patient had history of three consecutive tubal pregnancies (as per the previous records she carried), first two on the right side and third on the left. All conceptions were spontaneous.

The first pregnancy was right tubal ectopic pregnancy 6 years back for which laparotomy with salpingostomy was done as per the records. The second one, 4 years back, was again a right tubal ectopic, which had acute presentation at 6 weeks for which she underwent laparotomy with right sided total salpingectomy. The third ectopic pregnancy was 2 years back on left side which was managed medically. Fourth time, she presented with vaginal bleeding following 8 weeks of amenorrhoea. She was pale. Her pulse was hypovolemic with rate of 100/minute and blood pressure was 90/60 $\mathrm{mmHg}$. She had lower abdominal tenderness, more pronounced over left iliac fossa. Per vaginal examination revealed a soft bulky uterus, with an approximately $5 \times 5$ $\mathrm{cm}$ tender mass in the left fornix and fullness in pouch of Douglas. Transvaginal sonography (TVS) showed an empty uterine cavity with a left adnexal mass of $5 \times 5 \mathrm{~cm}$ with gestational sac with cardiac activity within, with significant free fluid in the pelvis (Figure 1). Patient was immediately shifted for emergency laparotomy along with simultaneous volume resuscitation. Her preoperative hemoglobin was $6.4 \mathrm{gm} \%$. Per-operative 
findings included hemoperitoneum of about 1 litre from the left ruptured ampullary tubal ectopic pregnancy. As the ruptured tube was not salvageable, total left salpingectomy was done. Patient received 3 units of packed cell transfusion along with 1 litre of crystalloids, during resuscitation. The histopathology confirmed the tubal ectopic pregnancy.

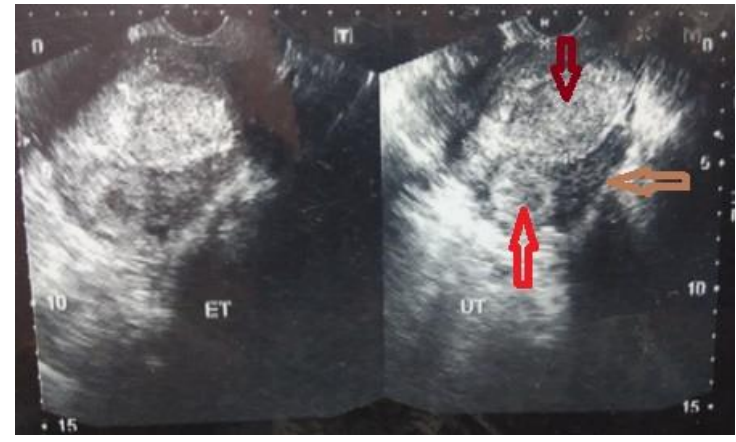

Figure 1: Grayscale transvaginal sonography showing adnexal mass (red arrow), free fluid (light brown arrow) and empty uterus (brown arrow).

\section{DISCUSSION}

After salpingectomy, the recurrence rate of tubal ectopic is lower than after salpingostomy. Recurrence rates after salpingectomy and salpingostomy are $10 \%$ and $15 \%$, respectively ${ }^{10}$.After medical treatment, the recurrence rates range from $10.2 \%$ to $18.7 \% .^{11,12}$

The common presentations of ectopic pregnancies are lower abdominal pain, vaginal bleeding with or without amenorrhoea and even acute hemorrhaghic shock requiring blood or blood component transfusion therapy. Being a life threatening emergency, it calls for early diagnosis and prompt management. The differential diagnosis includes other causes of acute abdomen like appendicitis, diverticulitis, colitis, typhlitis, ovarian neoplasms (torsion, haemorrhage or rupture), endometriosis, leiomyomas, acute pelvic inflammatory disease, urinary tract infection, ureteric calculi and pregnancy-related conditions like an on-going abortion.

Along with careful history and clinical examination, transvaginal ultrasonography and serial $\beta$-HCG monitoring has made the early diagnosis and management of the entity.

Expectant management, surgical or medical treatments are the treatment options for Ectopic pregnancy. Patients with low $(<1000 \mathrm{IU} / \mathrm{l})$ or declining HCG levels are candidates for expectant treatment. Hemodynamically unstable patients, heterotopic pregnancy with a viable intrauterine pregnancy, tubal rupture, contraindications to methotrexate and failed medical therapy are the indications for surgical treatment. ${ }^{13}$ Methotrexate therapy is given to patients who are hemodynamically stable, ectopic size $<4 \mathrm{~cm}$, compliant for post-treatment follow- up, $\beta$-HCG concentration $\leq 5000 \mathrm{mIU} / \mathrm{ml}$ and absent cardiac activity.

A high index of suspicion is important for the early diagnosis of ectopic gestations. In our case, the patient presented in an acute state with ectopic pregnancy in the only fallopian tube she had, in a non-salvageable state and in view of her previous history of recurrences of tubal ectopic pregnancies and unsalvageable status of the tube, it was excised. In this modern era, where "In Vitro Fertilisation and Embryo Transfer (IVF-ET)" is a readily available option, this decision was optimum. Moreover, since risk factors for ectopic pregnancies are same with Artificial Reproductive Techniques (ART) as for general population i.e. sexually transmitted diseases, history of previous tubal surgery, history of previous tubal damage, smoking and others, the decision of salpingectomy appeared to be in the patients interest. Even the risk of interstitial ectopic pregnancy after ART cannot be eliminated by salpingectomy. This calls for careful supervision of the ART achieved pregnancy, which, needless to say, is provided to all such pregnancies. From clinical point of view, if salpingectomy is considered, proximal tubal surgery (i.e. complete salpingectomy) should be done preferably as in future they can be referred for assisted reproductive techniques. Moreover, total salpingectomy also negates the chances of ectopic pregnancy in the diseased tubes. In our case, patient had $2^{\text {nd }}$ ectopic in the ipsilateral tube. Early diagnosis of ectopic in contralateral tube was possible in third pregnancy owing to a high index of suspicion and thus medical management was possible. Our patient presented with tubal rupture in fourth pregnancy. Earlier visit could have saved her laparotomy due to medical treatment option available, but the subsequent risk of recurrence wouldn't have decreased. In order to avoid morbidities due to surgery and multiple blood and blood component transfusion, it is necessary to educate such patients regarding risk of future recurrences and sensitise them for early antenatal visit as soon as their periods are overdue.

Thorough literature search on PubMed and Google Scholar using the MeSH terms, "consecutive", "recurrent", "four", "tubal ectopic" from January 1900 to December 2015 revealed only five case reports of consecutive three tubal ectopic. ${ }^{4-9}$ No case has been reported so far with four consecutive tubal ectopic pregnancies. While it was consecutive three ipsilateral ectopic pregnancies in three cases, ${ }^{6-8}$ bilateral tubes were involved in other two cases. ${ }^{4,5}$ Thus this case is extremely rare in its presentation as fourth consecutive ectopic. Patient was surgically managed and counselled and planned for In Vitro Fertilisation and Embryo Transfer (IVF-ET) for future pregnancy.

\section{CONCLUSION}

In patients with history of previous ectopic pregnancy a high chances of recurrence exists and thus a high index of suspicion should be maintained while attending to 
subsequent pregnancies in the first trimester. Decision for medical management and conservative surgical management should be opted for with utmost care in the light of best available current evidence.

Funding: No funding sources

Conflict of interest: None declared

Ethical approval: Not required

\section{REFERENCES}

1. Nabeshima H, Nishimoto M, Utsunomiya $H$, Arai M, Ugajin $\mathrm{T}$, Terada $\mathrm{Y}$, et al. Total laparoscopic conservative surgery for an intramural ectopic pregnancy. Diagn Therapeut Endosc. 2010;2010:504062.

2. Farquhar CM. Ectopic pregnancy. Lancet. 2005;366(9485):583-91.

3. Tulandi T. Reproductive performance of women after two tubal ectopic pregnancies. Fertil Steril. 1988;50(1):164-6.

4. Yildiz C, Karakus S, Bozoklu Akkar O, Yeniocak H, Cetim M. Three consecutive recurrent ectopic pregnancies: a case report. Basic Clin Sci. 2013;2:161-4

5. Afsaneh Tabandeh, Mahsa Besharat. Recurrent ectopic pregnancy in the fallopian tubes. J Clin Diagn Res. 2012 May;6(3 Suppl 1):493-4.

6. Adelusi B, Al-Meshari A, Akande EO, Chowdhury N. Three consecutive recurrent ectopic pregnancies. East Afr Med J. 1993 Sep;70(9):592-4.
7. Lema VM. Three consecutive ipsilateral tubal pregnancies in a nulliparous African woman: the role of conservative treatment. Cent Afr J Med. 1995 Feb;41(2):62-6.

8. Mathew M, Kumari R, Gowri V. Three consecutive ipsilateral tubal pregnancies. Int J Gynaecol Obstet. 2002 Aug;78(2):163-4.

9. Khan S, Hussain R. Recurrent tubal ectopic pregnancy. Pak J Med Dent. 2012;1(01):66-9.

10. Department of Health. Why mothers die? In: Department of Health, eds. The Report on Confidential Enquiries into Maternal Deaths in the United Kingdom 1997-1999. London: HMSO; 2001.

11. Luciano G. Nardo. The dilemma of recurrent ectopic pregnancy after tubal surgery and in vitro fertilization. What to do? Reprod Biomed Online. 2005 Mar;10(3):300.

12. Pisarska MD, Carson SA. Incidence and risk factors for ectopic pregnancy. Clin Obstet Gynecol. 1999;42(2-8):55-6.

13. Yao M, Tulandi T. Current status of surgical and nonsurgical management of ectopic pregnancy. Fertil Steril. 1997;67:421.

DOI: $10.5455 / 2320-1770.1 j \mathrm{rcog} 20150443$

Cite this article as: Pandey D, Nagar T, Sharma S, Salhan S. A rare case of fourth consecutive fallopian tube ectopic pregnancy. Int J Reprod Contracept Obstet Gynecol 2015;4:490-2. 